\title{
Implementation of BIPA in Higher Education: A Case Study at IAIN Batusangkar
}

\author{
Irwan $^{1}$, Atmazaki $^{2}$, Vivi Indriyani ${ }^{2}$, M. Aries Taufiq ${ }^{2}$ \\ ${ }^{1}$ IAIN Batusangkar, Indonesia, ${ }^{2}$ Universitas Negeri Padang \\ ${ }^{1}$ irwan@iainbatusangkar.ac.id, 2atmazaki@fbs.unp.ac.id, \\ ${ }^{3}$ vivi.indriyani93@gmail.com, ${ }^{4}$ ariespertama@gmail.com
}

\begin{abstract}
Language competence is one of the important things for education and work. At least one must have language skills other than the first language. Indonesian is one of the languages that are in great demand for foreigners to learn. The purpose of this study is to describe the implementation of BIPA in higher education, with a case study at IAIN Batusangkar. This research is a qualitative research. The data collection method used observation and interview techniques. The research instruments were observation sheets and interview guide sheets. Based on the results of the study it was found that there were several problems in the implementation of BIPA in IAIN Batusangkar. These problems include foreign students who have not attended BIPA before studying in tertiary education, BIPA scheduling, BIPA instructors have not experienced and trained, curriculum and learning tools are not well structured, and language differences between students' first languages.
\end{abstract}

Keywords: Foreign Language, BIPA, Higher Education

\section{PENDAHULUAN}

Salah satu tujuan utama dari sistem pendidikan nasional adalah agar individu memperoleh pengetahuan dan keterampilan yang diperlukan untuk bekerja ketika selesai menempuh pendidikan. Salah satu keterampilan yang semakin menonjol saat ini adalah kemampuan untuk berkomunikasi dalam bahasa asing [1]. Pembelajaran bahasa asing membuka dimensi dan pengalaman baru bagi siswa, serta memperluas wawasan [2]. Ada lebih dari dua bahasa yang digunakan di setiap negara dan tidak sulit untuk menemukan contoh dari sejumlah besar bahasa yang digunakan setiap hari [3].

Bahasa digunakan secara luas dalam teknologi, seni, sains, pariwisata, komunikasi internasional dan urusan internasional [4]. Bahasa merupakan salah satu kompetensi utama yang diperlukan dalam pengetahuan global dalam kaitannya dengan kemampuan komunikasi lisan dan tertulis dalam bahasa ibu dan setidaknya satu bahasa asing, terutama dalam bahasa Inggris [1]. Bahasa asing dapat diperoleh melalui pendidikan. Pendidikan bahasa asing adalah pendidikan antarbudaya. Membawa bahasa asing di kelas berarti menghubungkan siswa ke dunia yang secara budaya berbeda dari mereka [5]. Pengajaran bahasa sebagai bahasa asing berarti bahwa bahasa itu tidak hanya dalam batas-batasnya, tetapi juga berinteraksi dengan 
bangsa dan budaya lain, ia dipelajari lebih banyak agar diakui dan diajarkan dengan cara yang efektif [4].

Kemudahan dalam komunikasi dengan meluasnya penggunaan media massa, khususnya internet, telah membuat terjadinya komunikasi antar budaya, dan pada gilirannya menyebabkan pengakuan fenomenal dari 'lingua franca' [6]. Hal itu menyebabkan berbagai bangsa mengembangkan penggunaan bahasanya di kancah internasional, salah satunya bahasa Indonesia melalui pembelajaran BIPA (Bahasa Indonesia untuk Penutur Asing) [7]. Pemerintah Indonesia melalui program BIPA berusaha untuk memperkenalkan budaya Indonesia dan masyarakat di dunia Internasional [8]. Ini salah satu cara dalam membantu visi pemerintah untuk meningkatkan bahasa Indonesia menjadi bahasa internasional [9]. Salah satu faktor yang berpengaruh terhadap perkembangkan penggunaan bahasa Indonesia oleh penutur asing dengan diberlakukan Era Masyarakat Ekonomi Asean [10].

Arus globalisasi tidak selamanya membawa dampak buruk. Sebaliknya, hal tersebut dapat dimanfaatkan untuk melakukan perbaikan. Salah satunya yaitu dalam aspek bahasa. Arus globalisasi, modernisasi dan westernisasi mendorong Indonesia untuk menjadikan bahasanya dapat masuk dalam kancah internasional [7]. Bahasa Indonesia sebagai bahasa asing telah banyak menarik perhatian berbagai masyarakat mancanegara, mulai dari pejabat pemerintahan, wartawan, politikus, mahasiswa, pedagang, seniman, atau wisatawan [11]. Mempelajari bahasa Indonesia oleh warga negara asing dilatarbelakangi oleh berbagai tujuan, di antaranya untuk keperluan akademik, profesi, komunikasi, wisata dan rekreasi, melanjutkan studi ke Indonesia; ingin mengembangkan bisnis tertentu di Indonesia, ingin mendalami bahasa Indonesia, atau ingin mendalami kehidupan masyarakat dan budaya di Indonesia [11][12][13]. Alasan peningkatan minat mahasiswa asing untuk mempelajari bahasa Indonesia bisa didasari oleh kesadaran akan potensi bangsa Indonesia ditilik dari segi jumlah penduduk, politik, budaya, ekonomi, luas wilayah, serta pariwisata di mata internasional dan kesadaran tentang urgensi peningkatan fungsi bahasa Indonesia sebagai bahasa internasional sehingga dorongan untuk memantapkan pengajaran bahasa Indonesia sebagai bahasa asing semakin meningkat [14].

Keeksistensian bahasa Indonesia di kancah internasional dibuktikan dengan terdapat beberapa universitas di wilayah Asia dan daratan Eropa mengajarkan Bahasa Indonesia sebagai salah satu mata kuliah yang wajib dipelajari [7]. Bertambahnya pembelajar asing dan banyaknya lembaga penyelenggara BIPA mengindikasikan meningkatnya minat pembelajar asing untuk mempelajari bahasa Indonesia [9][15]. Bahkan, tercatat 219 lembaga di 48 negara sudah melaksanakan pembelajaran BIPA [11]. Beberapa negara baik di kawasan Asia, Eropa, Australia dan Amerika memiliki kelas BIPA yang dikhususkan bagi para mahasiswa asing yang ingin belajar bahasa Indonesia. BIPA telah menjadi bagian dari mata kuliah pilihan bahasa asing yang ditawarkan oleh beberapa universitas di berbagai negara [16].

Saat ini, peluang untuk memiliki pengalaman belajar di Indonesia untuk mahasiswa internasional semakin meningkat. Banyak lembaga pendidikan tinggi di Indonesia telah menyediakan program bagi mahasiswa internasional untuk melanjutkan pendidikan mereka di universitas negeri atau swasta [17]. Dapat dilihat bahwa maraknya mahasiswa asing yang belajar bahasa Indonesia secara langsung di Indonesia untuk keperluan akademik [12]. Berdasarkan data, jumlah siswa internasional di Indonesia pada tahun 2016 adalah 6.967. Selain itu, berdasarkan negara asal, sebagian besar siswa internasional berasal dari Timor Leste, Malaysia, Thailand, Korea Selatan, Cina, Jepang, Jerman, Belanda, Prancis, dan Australia [18]. Diindikasikan bahwa kelas BIPA telah menjadi salah satu program paling populer untuk siswa internasional [7]. Oleh karena itu, sebagai penutur asing yang mempelajari bahasa Indonesia di Indonesia, siswa asing mendapatkan kelebihan karena pembelajaran bahasa dilakukan dalam suatu budaya, negara, atau tempat bahasa itu digunakan [19]. 
Berdasarkan kajian peneliti sebelumnya, bahwa program BIPA masih terdapat tantangan dan kendala yang dapat timbul dari institusi, kurikulum, guru, materi kursus, perbedaan budaya, keterampilan belajar, gaya siswa, perbedaan alfabet dari bahasa target [4]. Tantangan dan kendala tersebut dijabarkan sebagai berikut. Pertama, ketidaktahuan mahasiswa asing tentang budaya Indonesia dapat menimbulkan kesalahpahaman atau menimbulkan kekacauan berbahasa [12]. Kedua, pelajar BIPA memiliki latar belakang bahasa dan budaya yang berbeda dengan bahasa yang dipelajarinya [11][20]. Ketiga, tingkat kemampuan pelajar BIPA berbedabeda [12]. Keempat, beragamnya tujuan pembelajar [15]. Kelima, kurangnya pemahaman terhadap karakteristik pelajar asing [21]. Keenam, perbendaharaan kata dalam bahasa yang dipelajari bisa ditemukan banyak aksen yang berbeda [21], dan mungkin mahasiswa tidak dapat melihat perubahan fonologis. Struktur kalimat bahasa target mungkin berbeda dari bahasa ibu mahasiswa, dan mereka mungkin mengalami kesulitan memahami peribahasa dan idiom dalam bahasa target [22]. Ketujuh, mahasiswa menemukan kesulitan untuk memahami dan mempraktikkan Bahasa Indonesia mereka dengan baik karena bingung membedakan antara Bahasa Indonesia dengan Bahasa Melayu [23]. Kedelapan, kurangnya bahan ajar yang variatif baik cetak maupun elektronik untuk dapat menunjang lancarnya proses belajar mengajar [8].

Agar tujuan pembelajaran BIPA berhasil, dapat dilakukan beberapa hal berikut ini. Pertama, pembelajaran BIPA perlu mempertimbangkan norma-norma pedagogis yang relevan dengan kebutuhan siswa [24]. Norma pedagogis dalam pemilihan strategi pembelajaran bahasa, materi yang diajarkan, maupun metode dan media pengajarannya adalah aspek penting yang perlu diterapkan guru dalam BIPA [21][25]. Kedua, pelaksanaan pengelolaan atau manajemen yang dilakukan oleh lembaga penyelenggara pengajaran BIPA [15]. Ketiga, penanganan dan pengelolaan kelas disesuaikan dengan karakteristik siswa BIPA [11][21][26]. Keempat, mengintegrasikan budaya Indonesia dalam pembelajaran BIPA [25][27][28]. Aspek budaya dapat mendukung penutur asing dalam berbahasa Indonesia sesuai dengan situasi dan kondisi masyarakat Indonesia [10]. Pengajar juga dapat membandingkan kebudayaan tempat asal mereka dengan kebudayaan yang ada di Indonesia sehingga mereka lebih paham dalam menangkap materi pembelajaran [29]. Kelima, keterampilan berbahasa (menyimak, berbicara, membaca, dan menulis) dipelajari secara keseluruhan. Sebagai sebuah sistem proses, optimalisasi pembelajaran BIPA bergantung pada ketuntasan di dalam pengelolaan keseluruhan unsurnya, baik secara secara simultan maupun bebas [21].

Berdasarkan latar belakang masalah tersebut, tujuan penelitian ini adalah untuk menjabarkan implementasi pelaksanaan BIPA di perguruan tinggi, dengan studi kasus di IAIN Batusangkar.

\section{METODE PENELITIAN}

Penelitian ini merupakan penelitian kualitatif. Metode pengumpulan data menggunakan teknik observasi dan wawancara [30]. Instrumen penelitian berupa lembar observasi dan lembar panduan wawancara. Narasumber penelitian ini antara lain, kepala unit pengembangan bahasa IAIN Batusangkar, instruktur BIPA IAIN Batusangkar, staf bagian kemahasiswaan, ketua prodi bahasa Inggris IAIN Batusangkar, mahasiswa BIPA IAIN Batusangkar. Mahasiswa asing di IAIN Batusangkar berasal dari dua negara yaitu Thailand dan Kamboja. Mereka menempuh pendidikan di IAIN Batusangkar dengan jurusan berbeda, antara lain bahasa Inggris, Bimbingan Konseling, Hukum Keluarga dan Ekonomi Islam. 


\section{HASIL DAN PEMBAHASAN}

Pemerintah pusat bukanlah sat-satunya pihak yang bertanggung jawab untuk upaya internasionalisasi Bahasa Indonesia, salah satu upaya yang dapat dilakukan melalui pengajaran BIPA di universitas-universitas baik di dalam maupun di luar negeri [7]. Salah satu institusi yang melaksanakan program BIPA adalah Institut Agama Islam Negeri (IAIN) Batusangkar. Kebijakan menerima mahasiswa asing di IAIN Batusangkar sudah dimulai dari tahun 2016. Penerimaan mahasiswa asing sudah dianggarkan dalam DIPA IAIN Batusangkar untuk tahun 2018 dan tahun 2019. Pada tahun tersebut, IAIN Batusangkar sudah menerima 4 orang mahasiswa asing dari Thailand dan pada tahun 2019 menerima 4 orang mahasiswa asing dari Kamboja. Dalam pelaksanaan BIPA tersebut masih ditemukan beberapa kendala. Hal tersebut akan dijabarkan sebagai berikut.

Permasalahan pertama adalah mahasiswa asing tersebut tidak memiliki kemampuan dasar berbahasa Indonesia. Selain itu, mereka juga tidak memiliki kemampuan berbahasa Inggris. Hanya satu mahasiswa yang berasal dari Thailand bisa berbahasa Melayu. Mereka sebelum menempuh perkuliahan di Indonesia belum mengikuti pelatihan BIPA sehingga hal tersebut dapat menimbulkan kendala dalam belajar. Berdasarkan hasil wawancara ditemukan bahwa sebelum memulai perkuliahan, mereka idealnya harus belajar bahasa Indonesia. Akan tetapi, jadwal kedatangan mahasiswa asing tersebut ke Indonesia sekitar tiga hari sebelum perkuliahan dimulai, maka mereka tidak bisa belajar bahasa Indonesia. Idealnya, mahasiswa asing yang akan menempuh pendidikan di Indonesia harus mempelajari bahasa Indonesia terlebih dahulu sebelum menempuh pendidikan formal di universitas yang diinginkan [12]. Siswa dengan pengalaman belajar bahasa sebelumnya tahu bagaimana mempelajari suatu bahasa dan kosa katanya [2].

Mahasiswa asing yang menempuh perkuliahan di IAIN Batusangkar tinggal di asrama. Jadwal pembelajaran bahasa Indonesia disediakan hanya dua kali seminggu dengan durasi empat jam pelajaran setiap pertemuan. Permasalahan lain yang ditemukan adalah penyusunan jadwal pembelajaran bahasa Indonesia untuk mahasiswa asing. Mereka memiliki jadwal perkualihan yang tidak sama, sehingga kadang-kadang jadwal pembelajaran tumpang tindih dengan perkuliahan reguler. Belajar bahasa Indonesia untuk siswa BIPA berbeda dengan belajar siswa domestik [28]. Untuk mengikuti kuliah di perguruan tinggi di Indonesia memerlukan pengetahuan bahasa Indonesia sesuai dengan bidang ilmu yang diikuti (ilmu sosial, ekonomi, teknik, dan sebagainya) [21]. Akan tetapi, jurusan yang ditempuh oleh mahasiswa asing di IAIN Batusangkar berbeda-beda. Hal itu dapat berpengaruh terhadap proses pembelajaran [20]. Selain itu, jurusan dan kelas belajar reguler yang berbeda, membuat siswa memiliki jadwal perkuliahan yang berbeda, sehingga penyesuaian jadwal untuk pembelajar BIPA belajar bahasa Indonesia memiliki kendala juga dari segi waktu belajar.

Di IAIN Batusangkar belum memiliki instruktur BIPA yang berpengalaman dan terlatih. Dari pengajar bahasa Indonesia di institusi tersebut, hanya ada dua orang dosen bahasa Inggris yang pernah mengikuti pelatihan pengajar BIPA. Dosen tersebut juga pernah mengajar BIPA sebelumnya. Selain itu, proses pembelajaran BIPA di IAIN Batusangkar hanya berlangsung alami, meskipun masih ada sedikit berpedoman kepada konsep-konsep pembelajaran BIPA. Persiapan pengajar dalam mengajar BIPA belum terencana dengan baik sehingga Kurikulum pembelajaran BIPA belum tersusun dengan baik, bahan ajar seperti buku teks, modul, dan bahan ajar lain belum lengkap tersedia, media pembelajaran yang representatif belum tersedia, serta alat dan perangkat evaluasi pengajaran BIPA juga belum tersusun baik.

Sebelum mengajar BIPA, pengajar seharusnya telah merencanakan tujuan pembelajaran yang akan dicapai agar proses pelaksanaan pembelajaran memiliki target dan tidak menyimpang 
[31]. Mereka juga perlu mempertimbangkan norma-norma pedagogis yang relevan dengan kebutuhan siswa, pemilihan bahan ajar dan strategi pembelajaran [24][25]. Unsur-unsur lain yang terlibat yang perlu dipersiapkan oleh pengajar, antara lain media, evaluasi, dan pengelolaan kelas [21]. Untuk mengakomodasi minat dan kebutuhan yang mungkin berbeda dari yang satu dengan yang lain perlu disiapkan materi yang bervariasi [20]. Namun, temuan oleh peneliti sebelumnya menunjukkan bahwa peningkatan kuantitas peserta BIPA tidak dibarengi dengan peningkatan bahan ajar dan media pembelajaran yang dapat mendukung lancarnya pelaksanaan program [8].

Pengajaran BIPA di IAIN Batusangkar diserahkan pengelolaannya kepada Unit Pengembangan Bahasa. Instruktur BIPA dibayar 50.000,- per jpl atau sebesar 200.000,- untuk setiap pertemuan dengan durasi 200 menit. Berdasarkan wawancara ditemukan bahwa anggaran untuk pembelajaran BIPA belum memadai. Hal tersebut juga berdampak pada sarana dan prasarana untuk pengajaran BIPA tersebut. Beberapa fasilitas yang dibutuhkan untuk mengajaran BIPA tidak tersedia, sehingga proses pembelajaran tidak terlaksana dengan maksimal. Selain strategi, metode, bahan ajar, evaluasi, dan sebagainya, keberhasilan pembelajaran BIPA juga ditentukan oleh pelaksanaan manajemen atau pengelolaan yang dilakukan oleh lembaga penyelenggara pengajaran BIPA [15]. Lingkungan belajar yang tepat adalah elemen penting dalam pengajaran bahasa. Jika siswa dapat dilengkapi dengan lingkungan yang positif untuk pembelajaran bahasa mereka, ini akan membantu siswa mencapai keterampilan bahasa [11]. Sangat penting untuk mengembangkan kualitas kelas BIPA untuk siswa internasional di universitas [17].

Persoalan lain yang ditemukan adalah adanya perbedaan tulisan antara aksara latin dengan aksara Thailand dan aksara Kamboja. Sebelum belajar bahasa Indonesia, mahasiswa tersebut harus memahami aksara latin terlebih dahulu. Mereka juga mengalami kesulitan dalam memahami kosakata bahasa Indonesia karena struktur kalimat bahasa Indonesia berbeda jauh dengan bahasa ibu mereka. Pengajar BIPA juga tida memahami sedikitpun bahasa Thailand dan bahasa Kamboja. Jadi, ketika pengajar ingin memberikan penjelasan kepada mahasiswa tersebut, hanya dibantu dengan gerak isyarat (gesture) saja.

Pelajar asing mungkin mengalami kesulitan dalam membangun unit tata bahasa dan struktur tertentu karena beberapa alasan yang timbul dari kenyataan bahwa bahasa target berasal dari struktur keluarga bahasa yang berbeda dari bahasa ibu mereka [4]. Karena perbedaan sistem bahasa, menyebabkan pelajar BIPA banyak menghadapi kesulitan terutama dalam masalah pelafalan dan penulisan [21]. Perbendaharaan kata dalam bahasa yang dipelajari bisa ditemukan banyak aksen yang berbeda [32], dan mungkin mahasiswa tidak dapat melihat perubahan fonologis dan mereka mungkin mengalami kesulitan memahami peribahasa dan idiom dalam bahasa yang dipelajari [22].

\section{SIMPULAN}

Berdasarkan hasil dan pembahasan, dapat disimpulkan bahwa terdapat beberapa permasalahan dalam implementasi BIPA di IAIN Batusangkar. Beberapa permasalahan tersebut adalah sebagai berikut. Pertama, adalah mahasiswa asing belum memiliki kemampuan dasar berbahasa Indonesia. Kedua, sulit dalam penyusunan jadwal pembelajaran bahasa Indonesia untuk mahasiswa asing karena mahasiswa tersebut menempuh jurusan yang berbeda dan jadwal perkuliahan yang berbeda. Ketiga, di IAIN Batusangkar belum memiliki instruktur BIPA yang berpengalaman dan terlatih. Keempat, kurikulum dan perangkat pembelajaran belum tersusun dengan baik. Kelima, sarana dan prasarana pembelajaran belum lengkap dan memadai. Kelima, 
perbedaan tulisan antara aksara latin dengan aksara Thailand dan akasara Kamboja (bahasa pertama mahasiswa asing) sehingga mereka harus mempelajari aksara latin terlebih dahulu.

\section{REFERENCES}

[1] Y. Doğan and M. Tuncer, "Examination of foreign language classroom anxiety and achievement in foreign language in Turkish University students in terms of various," $J$. Educ. Train. Stud., vol. 4, no. 5, pp. 18-29, 2016.

[2] A. Orhan, "The experiences of students in English language teaching on learning 'German as a foreign language,"' J. Educ. Learn., vol. 8, no. 4, pp. 112-123, 2019.

[3] K. Johnson, An introduction to foreign language learning and teaching (Sec. Ed.). New York: Pearson Education Limited, 2008.

[4] T. G. Ari and F. Kayalar, "Language teachers' suggestions over coping with difficulties in Turkish language teaching to foreigners," Int. J. Lang. Educ. Teach., vol. 6, no. 2, pp. 404-412, 2018.

[5] Ş. E. Yilmaz, "The impulse of class tutoring activities evaluated in the light of foreign language teaching methods," Int. J. Lang. 'Educ. Teach., vol. 5, no. 2, pp. 290-300, 2017.

[6] J. Jenkins, "English as a Lingua Franca : interpretations and attitudes," World Englishes, vol. 28, no. 2, pp. 200-207, 2017.

[7] R. K. Ningrum, H. J. Waluyo, and R. Winarni, "BIPA (bahasa indonesia penutur asing) sebagai upaya internasionalisasi universitas di Indonesia," in The 1st Education and Language International Conference Proceedings, 2015, pp. 726-732.

[8] N. L. P. S. Adnyani, I. M. S. Paramarta, P. A. P. Sudana, I. N. Suparwa, and M. S. Satyawati, "Pengembangan bahan ajar BIPA kontekstual berbasis budaya lokal Bali," in Seminar Nasional Riset Inovatif II, 2014, pp. 73-77.

[9] E. P. Saputro and S. Arikunto, "Keefektifan manajemen program pembelajaran bipa (bahasa indonesia bagi penutur asing) di kota Yogyakarta," J. Akuntabilitas Manaj. Pendidik., vol. 6, no. 1, pp. 123-138, 2018.

[10] N. Budiana, S. A. Indrowaty, and R. D. Ambarastuti, "Pengembangan buku teks BIPA berbasis multikulturalisme bagi penutur asing tingkat pemula," Diglossia, vol. 9, no. 2, pp. 108-122, 2018.

[11] J. Susilo, "Pengembangan kurikulum bahasa Indonesia bagi penutur asing," DeiksisJurnal Pendidik. Bhs. dan Sastra Indones., vol. 3, no. 1, pp. 44-53, 2016.

[12] M. Yahya, Andayani, and K. Saddhono, "Tendensi kesalahan sintaksis bahasa tulis pembelajar bahasa Indonesia bagi penutur asing (BIPA)," Skma J. Pendidik., vol. 2, no. 1, pp. 137-166, 2018.

[13] A. Kusmiatun, Mengenal BIPA (bahasa Indonesia bagi penutur asing) dan pembelajarannya. Yogyakarta: K-Media, 2016.

[14] F. Pangesti and A. B. Wurianto, "Pengembangan bahan ajar BIPA berbasis lintas budaya melalui pendekatan kontekstual-komunikatif," J. Pendidik. Bhs., vol. 7, no. 2, pp. 342-353, 2018.

[15] N. P. A. W. Sar, I. M. Sutama, and I. M. Sutama, "Pembelajaran bahasa Indonesia bagi penutur asing (BIPA) di sekolah Cinta Bahasa, Ubud, Bali," e-Journal Prodi Bhs. dan Sastra Indones., vol. 5, no. 3, 2016.

[16] Hertiki, "Pengajaran dan pembelajaran BIPA di perguruan tinggi Polandia," $J$. Pendidik. Bhs. dan Sastra Indones., vol. 6, no. 2, pp. 2-6, 2017.

[17] L. C. Aguskin and Maryani, "Exploring the international students' perception of the 
Indonesia Teaching materials to enchance their willingness to communicate," Ling. Cult., vol. 12, no. 4, pp. 323-331, 2018.

[18] Ristekdikti, "Perguruan Tinggi Indonesia diminati mahasiswa asing," 2017. [Online]. Available: https://ristekdikti.go.id/perguruan-tinggi-indonesiadiminati-mahasiswaasing-2/. [Accessed: 13-Oct-2019].

[19] S. A. Ningsih, Y. Rasyid, and L. Muliastuti, "Analisis kebutuhan materi ajar membaca Bipa A1 dengan pendekatan deduktif di SD D'Royal Maroco," PembelajarJurnal Ilmu Pendidikan, Keguruan, dan Pembelajaran, vol. 2, no. 2, 2018.

[20] I. Suyitno, "Aspek budaya dalam pembelajaran bahasa Indonesia bagi penutur asing (BIPA)," in Bahasa dan Sastra Indonesia dalam Konteks Global, 1997, pp. 55-70.

[21] I. Suyitno, "Pengembangan bahan ajar bahasa Indonesia untuk penutur asing (BIPA) berdasarkan hasil analisis kebutuhan belajar," Wacana, vol. 9, no. 1, pp. 62-78, 2007.

[22] L. S. Stæhr, "Vocabulary knowledge and advance listening comprehension in English as a foreign language," Stud. Second Lang. Acquis., vol. 31, no. 4, pp. 577-607, 2017.

[23] L. Nurlina and E. S. Israhayu, "BIPA learning material development for empowering Thailand students' writing competence," Int. J. Educ. Stud., vol. 7, no. 1, pp. 57-66, 2014.

[24] I. Suyitno, G. Susanto, M. Kamal, and A. Fawzi, "Cognitive learning strategy of BIPA students in learning the Indonesian language," IAFOR J. Lang. Learn., vol. 3, no. 2, pp. 175-190, 2017.

[25] E. R. Maharany, "Cerita rakyat sebagai media keterampilan berbahasa," J. Inov. Pendidik., vol. 1, no. 2, pp. 12-18, 2017.

[26] F. Kayalar and F. Kayalar, "The effects of auditory learning strategy on learning skills of language learners (students ' views)," IOSR J. Humanit. Soc. Sci., vol. 22, no. 10, pp. 4-10, 2017.

[27] R. Suher and P. Hermoyo, "Pengembangan materi ajar BIPA melalui budaya lokal Jawa Timur," ELSE (Elementary Sch. Educ. Journal), vol. 1, no. 1, pp. 48-56, 2017.

[28] S. Sujinah, D. Setyorini, S. Yunianti, Ngatmain, and E. S. Isnah, "Developing reading comprehension assessment based adobe flash CC2015 for BIPA intermediate level," Humanit. Soc. Sci. Rev., vol. 7, no. 3, pp. 460-466, 2019.

[29] A. M. N. S, Andayani, and K. Saddhono, "The use of writing learning media for BIPA students to understand local culture," Komposisi, vol. XVIII, no. 1, pp. 66-79, 2017.

[30] K. E. Johnson and R. E. Stake, “The Art of Case Study Research,” Mod. Lang. J., 2006.

[31] R. Ramliyana, "Penerapan media komik pada pembelajaran BIPA (Studi kasus pada peserta Korea tingkat pemula di Universitas Trisakti Jakarta)," J. SAP, vol. 1, no. 1, pp. $8-17,2016$.

[32] J. Scales, A. Wennerstrom, D. Richard, and S. H. Wu, "Language learners' perceptions of accent," TESOL Q., vol. 40, no. 4, pp. 715-728, 2012. 